\title{
Two Phenolic Compounds from Chloroform Fraction of Syzygium Polycephalum MIQ. Stem Bark (Myrtaceae)
}

\author{
Tukiran $^{1, *}$, Andika Pramudya Wardhana ${ }^{1}$, Nurul Hidajati ${ }^{1}$, Kuniyoshi Shimizu ${ }^{2}$ \\ ${ }^{1}$ Department of Chemistry, Faculty of Mathematics and Natural Sciences, Universitas Negeri Surabaya, \\ Surabaya, Indonesia \\ ${ }^{2}$ Department of Forests and Forest Products Sciences, Faculty of Agriculture, Kyushu University, Fukuoka, \\ Japan \\ *email: tukiran@unesa.ac.id
}

Received October 12, 2017; Accepted April 24, 2018; Available online May 31, 2018

\begin{abstract}
Syzygium polycephalum (Kupa) is a plant of the Myrtaceae family which is one of the endemic plants in Indonesia, commonly called as Gowok. The chemical components of the plant have not been reported so far. This study is intended to know the molecular structures of isolated compounds of chloroform fraction from $S$. polycephalum stem bark. The steam bark of the plant is dried, powdered and macerated with methanol to yield methanolic extract. The methanolic extract was then conducted to fractionation using hexane and chloroform to obtain hexane and chloroform fractions. The chloroform fraction was further subjected to separation using column chromatography to obtain pure isolates and followed by measuring of their spectroscopic evidences. The isolation of chloroform fraction had led to the findings of two pure isolates. Their structures of isolates were elucidated by extensive spectroscopic methods and by comparison with the literature data to gain two phenolic compounds that are gallic acid and 3,4,3'-tri- $O$-methylellagic acid.
\end{abstract}

Keywords: 3,4,3'-tri- $O$-methylellagic acid, gallic acid, Myrtaceae, phenolic compound, $S$. polycephalum.

\section{INTRODUCTION}

Myrtaceae family has about 130 genera and approximately $3800-5800$ species of predominantly tropical and subtropical distribution. The Myrtaceae family is known to possess leaves with high concentrations of terpenes and considerable qualitative and quantitative variation in the types of terpenes, according to taxonomic identity and population and individual levels. These variations have pharmacological potential and many industrial applications (Barbosa, Cleber, Róbson, Renata, \& Antônio, 2013).

One important genera of this family is Syzygium, which is one of the larger genera with around 500 species. They are usually trees and shrubs distributed in the tropics of the world from Africa to the West Pacific with major concentration in Malaysia. The genus is popular for the spice plant, i.e. Syzygium aromaticum (L.) Merr. \& Perry which is native to Maluku Islands in Indonesia (Mohanan et al., 2015).

Syzygium can be found from sea level on swamp forests, lowland and montane forests to subalpine forests. Their habits are also vary, from canopy-emergent trees to canopy trees, understorey trees, treelets and shrubs. Indonesian Botanic Gardens (Bogor, Cibodas,
Purwodadi and Bali) have collected 40 species of Syzygium from all over Indonesia. Purwodadi Botanic Garden has collection of 15 species of Syzygium, 5 of which were from East Java. This number is still quite low compared to the total species of Syzygium in East Java (Ariyanti, Rony, Lia, \& Deden, 2012).

The species of syzygium genus is well known for its medicinal properties. $S$. jambolana ( $S$. cumini), popularly known as Jamun, has been the main ingredient of various medications of the traditional Indian system of medicine. Preclinical studies have shown that the various extracts of $S$. jambolana possess a range of pharmacological actions, such as antibacterial, antifungal, antiviral, antiulcerogenic, cardioprotective, anti-allergic, hepatoprotective and anti-diarrheal effects, thereby supporting its myriad traditional uses (Baliga, Harshith, Bantwal, Rajesh, \& Princy, 2011). Studies in the past one decade have shown that Jamun possess antineoplastic, radioprotective and chemopreventive effects all of which are useful in the prevention and treatment of cancer (Preddy, 2014).

$S$. aqueum is a species of brush cherry tree. It is commonly known as water apple or water cherry. It is well documented as a 
medicinal plant, and various parts of the tree have been used in traditional medicine, for instance as an antibiotic. S. aqueum leaf extracts have a significant composition of phenolic compounds, protective activity against free radicals as well as low pro-oxidant capability (Palanisamy et al., 2011).

The Syzygium species having appreciable medicinal properties have drawn the attention of the researchers in recent times included $S$. polycephalum. S. polycephalum, locally known as gowok or kupa or kepa, is an indigenous tree growth in Indonesia. It has synonyms: Eugenia polycephala Miq., Jambosa cauliflora DC., Jambosa polycephala (Miq.) Miq. and S. cauliflorum (DC.) Bennet. Gowok is indigenous to West and Central Malesia. It is common in Java and Kalimantan in Indonesia. It has been reported the presence of several compounds found in the plant that are ursolic acid, oleanolic acid, squalene, and $\beta$-sitosterol from $S$. polycephalum leaves (Ragasa et al., 2014). It could be considered that all of these compounds are non phenolic compounds.

On the other hand, it was reported that the wood extracts (ethyl acetate extract) of $S$. polychephalum potentially contain anti-fungal compound (i.e. 3-O-glucosyl-3',4',5trihydroxyflavonol) to inhibit the growth of $S$. commune Fr. and Pleurotus sp fungi (Jemi, Syafii, Ferbianto, \& Hanafi, 2010). Using the literature searching, there are no reports regarding the phenolic compounds of the stem bark of S. polycephalum. Therefore, it was of great interest to carry out a proper scientific investigation of the stem bark extract of this plant. The present study however, reports for the first time the isolation and structural elucidation of gallic acid (1) and 3,4,3'-tri- $O$ methylellagic acid (2) from the chloroform fraction of the stem bark of S. polycephalum.

\section{EXPERIMENTAL SECTION}

\section{Materials}

\section{Chemicals and plant materials}

The solvents used in this study are hexane, chloroform, ethyl acetate, and methanol that were of pro-analytical Grade (Grade AR) and silica gel obtained from E. Merck (Germany). The stem bark of $S$. polycephalum (c.a. $27 \mathrm{~kg}$ ) was collected from a local area in Ngawi, East Java, Indonesia in December 2014. The identification of the plant was performed by staff of Herbarium-LIPI, Purwodadi, East Java, Indonesia. A voucher sample is kept in the Herbarium of LIPI with Identification No. 0117/IPH.06/HM/I/2015, January 5, 2015.

\section{Equipment and instruments}

The equipment used to do extraction and fractionation (isolation) are filter paper, Buchner funnel, Hirsch funnel, Erlenmeyer flask, pippet, spatula, measuring glass, vials, containers, separating funnel, and vacuum rotary evaporator type BUCHI Rotavapor R-215. The equipment used to measure melting point of isolate is Fisher Scientific. Whereas, chromatographic techniques used to isolate phenolic compounds from chloroform fraction included Vacuum Liquid Chromatography (VLC) (using silica gel 60, 0.040-0.063 mm), Gravitational Column Chromatography (GCC) (silica gel 60, 0,063-0,200 $\mathrm{mm}$ and 0,200$0,500 \mathrm{~mm}$ or $70-230$ mesh ASTM), TLC analyses were carried out on silica gel 60 F254 chromaplates with the developing solvent systems. Checking the homogeneity of the compounds were made by TLC on Kieselgel gel 60 F254 pre-coated sheets (E.Merck) and the spots were detected by exposure to UVlamp at $254 \mathrm{~nm}$ or $366 \mathrm{~nm}$.

A number of instruments needed to identify and characterize an isolate included spectrophotometer FTIR-8400S SHIMADZU, spectrophotometer UV-1800 SHIMADZU. The ${ }^{1} \mathrm{H}$ NMR spectra were recorded with a Bruker DRX-600 NMR Spectrometer $(600 \mathrm{MHz}$, $\left.\mathrm{CD}_{3} \mathrm{OD}\right)$ instrument and the ${ }^{13} \mathrm{C}$ NMR spectra were obtained with the same instrument at 150 $\mathrm{MHz}$ in $\mathrm{CD}_{3} \mathrm{OD}$. Chemical shifts are given in $\delta$ (ppm) values relative to those of the solvent signal $\left[\mathrm{CD}_{3} \mathrm{OD}(\delta \mathrm{H} 3.30 ; \delta \mathrm{C} 49.0)\right]$ on the tetramethylsilane (Sigma) scale.

\section{Procedures \\ Preparation of methanolic extract and its fractionation of S. polycephalum stem bark}

Stem bark of $S$. polycephalum (Gowok) was cleaned and cut into small using commercial cutter, dried in under sunlight during c.a. one week and powdered. The powder was then macerated using methanol as extracting solvent for a day. Macerate was filtered and evaporated using vacuum rotary evaporator to yield methanolic extract. The extract was then added with a little of methanol and was fractionated using hexane. The residue of methanol extract was further fractionated 
again using chloroform and the last extract was subjected to investigate the chemical constituents.

\section{Isolation and characterization of pure isolates}

The stem bark of $S$. polycephalum was macerated in $\mathrm{MeOH}$ at room temperature for $24 \mathrm{~h}$ and then filtered. The filtrate was concentrated under vacuum to give $349 \mathrm{~g}$ of crude residue. The crude $(349$ g) was suspended in methanol and defatted with hexane to gain hexane extract (22.38 g). This process was also repeatedly carried out by using chloroform to yield chloroform extract $(5.66 \mathrm{~g})$. The chloroform extract was then subjected to column chromatography (silica gel, $n$-hexane, $n$-hexane- $\mathrm{CHCl}_{3}$ and $\mathrm{MeOH}$, in order of increasing polarity) yielding 55 fractions that can be grouped to be 5 fractions [A (1-4), B (5-6), C (7-37), D (38-51), and E (52-55)]. The fraction A (1-4) was allowed to evaporate at room temperature and yielded a pure isolate as colorless needle crystal $(10 \mathrm{mg})$ with mp. 256-257 ${ }^{\circ} \mathrm{C}$. The crystal was characterized by UV-Vis and FTIR and by comparison with literature data and determined its structure to be gallic acid (1). Then, fraction B (5-6) seemed that the fraction gave simple chromatogram profile and allowed to dry at fume hood yielded a pure enough isolate as off-white amorphous powder $(10.3 \mathrm{mg})$ with mp. 267-269 ${ }^{\circ} \mathrm{C}$. The isolate was then characterized by UV-Vis, FTIR, LCMS and NMR spectroscopies and by comparison with literature data and determined its structure to be 3,4,3'-tri-O-methylellagic acid (2).

\section{RESULTS AND DISCUSSION}

The $\mathrm{MeOH}$ extract of $S$. polycephalum stem barks was partitioned successively with hexane and $\mathrm{CHCl}_{3}$. Successive column chromatography of the $\mathrm{CHCl}_{3}$ extract over silica gel using the various chromatographic techniques yielded compounds $\mathbf{1}$ and $\mathbf{2}$.

Gallic acid (1): a colorless needle crystal; MP. 256-257 ${ }^{\circ} \mathrm{C}$; UV-Vis $(\mathrm{MeOH}$, $\left.\lambda_{\max }\right): 216$ and $271 \mathrm{~nm}$; IR $\left(\mathrm{KBr}, v_{\max }\right):=3497$, 3368 , 3292, 3065, 3005, 1709, 1620, 1541, 1443, 1246, 1026, and $702 \mathrm{~cm}^{-1}$; Authentic sample (gallic acid), as shown in Figure 1.

An ellagic acid derivative, 3,4,3'-tri-Omethylellagic acid (2): a white amorphous powder; MP. 267-269 ${ }^{\circ} \mathrm{C}$; UV $\left(\mathrm{MeOH}, \lambda_{\max }\right)$; 247 and $371 \mathrm{~nm}$; IR $\left(\mathrm{KBr}, v_{\max }\right):=3441,2957$, 2918, 2851, 1753, 1728, 1611, 1578, 1493,
1361, 1298, 1115, 1092, 988 and $914 \mathrm{~cm}^{-1} ;{ }^{1} \mathrm{H}$ NMR (600 MHz, DMSO- $d 6, \mathrm{ppm}): \delta(\mathrm{ppm})=$ $7.61(1 \mathrm{H}, \mathrm{s}, \mathrm{H}-5)$ and $7.52(1 \mathrm{H}, \mathrm{s}, \mathrm{H}-5$ '), 3.31 $(1 \mathrm{H}, b r, \mathrm{OH}), 4.06,4.04$, and $3.99(3 \mathrm{H}, \mathrm{s}$, $\left.\mathrm{OCH}_{3}\right) ;{ }^{13} \mathrm{C}$ NMR (150 MHz, DMSO- $\left.d 6\right): \delta$ $(\mathrm{ppm})=158.52(\mathrm{C}, \mathrm{C}-7), 158.32\left(\mathrm{C}, \mathrm{C}-7^{\prime}\right)$, 153.71 (C, C-4), 153.06 (C, C-4'), 112.49 (C, C-5), 107.44 (C, C-5'), 141.48 (C, C-3), 140.28 (C, C-3'), 140.95 (C, C-2), 140.77 (C, C-2'), 113.44 (C, C-6), 111.84 (C, C-6'), 111.76 (C, C-1), 110.89 (C, C-1'); LC-ESI-MS $\left(\mathrm{m} / \mathrm{z} 345.39\left[\mathrm{M}+\mathrm{H}^{+}\right]\right.$for $\mathrm{C}_{17} \mathrm{H}_{12} \mathrm{O}_{8}$, as shown in Figure 2.

Compound 1 was obtained as a colorless needle crystals $(10 \mathrm{mg}), \mathrm{m} . \mathrm{p} .256-257^{\circ} \mathrm{C}$. The UV-Vis $\left(\mathrm{MeOH}, \lambda_{\max }\right)$ spectrum of compound 1 showed maximum absorption at 216 and 271 $\mathrm{nm}$ indicating a phenolic compound

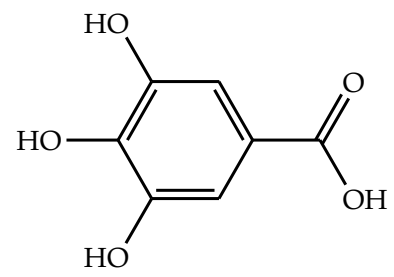

Figure 1. Structure of gallic acid (1) isolated from $S$. polycephalum stem bark.<smiles>COc1cc2c(=O)oc3c(OC)ccc4c(=O)oc(c1OC)c2c34</smiles>

Figure 2. Structure of 3,4,3'-tri- $O$ methylellagic acid (2) isolated from $S$. polycephalum stem bark.

The IR $\left(\mathrm{KBr}, v_{\max }\right)$ spectrum exhibited the following absorption frequencies: 3497,3368 , 3292 , 3065, 3005, 1709, 1620, 1541, 1443, 1246,1026 , and $702 \mathrm{~cm}^{-1}$. The IR spectrum of it showed absorption bands broadly at 3497 , $3368,3292,3065$, and $3005 \mathrm{~cm}^{-1}$ indicating hydroxyl group and at $1709 \mathrm{~cm}^{-1}$ indicating carbonyl group. The absorption bands at 1620 , 1541 , and $1443 \mathrm{~cm}^{-1}$ indicated benzene ring system. For a while, absorption bands at 1246 and $1206 \mathrm{~cm}^{-1}$ indicated the presence of three -O-aryl groups directly attached at the benzene ring in which two of their groups are similar, 
namely meta-position toward carbonyl group. The last absorption band at $702 \mathrm{~cm}^{-1}$ showed substituted benzene. By comparing the IR data of compound $\mathbf{1}$ with that of authentic sample (gallic acid) and those reported in literature data (Tukiran, Mahmudah, Hidayati, \& Shimizu, 2016), it was confirmed as gallic acid (1).

Compound 2 was obtained as an offwhite amorphous powder (10.3 mg), m.p. 267$269{ }^{\circ} \mathrm{C}$ and its molecular formula $\mathrm{C}_{17} \mathrm{H}_{12} \mathrm{O}_{8}$ was determined by the LC-ESI-MS $(\mathrm{m} / \mathrm{z}$ $\left.345.39\left[\mathrm{M}+\mathrm{H}^{+}\right]\right)$. The UV-Vis $\left(\mathrm{MeOH}, \lambda_{\max }\right)$ spectrum of compound $\mathbf{2}$ showed maximum absorption at 247 and $371 \mathrm{~nm}$ indicating phenolic compound with conjugated benzene ring of carbonyl group. The IR (KBr, $\left.v_{\max }\right)$ spectrum exhibited the following absorption frequencies: $3441,2957,2918,2851,1753$, 1728, 1611, 1578, 1493, 1361, 1298, 1115, 1092,988 and $914 \mathrm{~cm}^{-1}$. The IR spectrum of it showed sharp absorption bands at $3441 \mathrm{~cm}^{-1}$ indicating hydroxyl group, at 2957, 2918, and $2851 \mathrm{~cm}^{-1}$ representing C-H stretching, and at 1753 and $1728 \mathrm{~cm}^{-1}$ revealing the presence of two carbonyl groups. The characteristic absorption bands at 1611,1578, and $1493 \mathrm{~cm}^{-1}$ indicated benzene ring system. The presence of methyl group is shown specifically at 1361 $\mathrm{cm}^{-1}$. For a while, absorption bands at 1298, 1115 and $1092 \mathrm{~cm}^{-1}$ indicated -O-aryl and -O$\mathrm{CH}_{3}$, respectively. The last absorption band at 988 and $914 \mathrm{~cm}^{-1}$ showed substituted benzene.

The ${ }^{1} \mathrm{H}-\mathrm{NMR}$ spectrum $(600 \mathrm{MHz}$, DMSO- $d 6, \mathrm{ppm}$ ) of compound 2 revealed the presence of six significant proton signals that could be explained as follows. Two signals located at $\delta_{\mathrm{H}} 7.61(1 \mathrm{H}, \mathrm{s})$ and $7.52(1 \mathrm{H}, \mathrm{s})$ indicated two aromatic protons due to the ellagic acid skeleton. The spectrum of the compound also displayed one signal at $\delta_{\mathrm{H}} 3.31$ $(1 \mathrm{H}, \quad b r)$ suggesting the presence of an aromatic hydroxyl group (aryl $-\mathrm{OH}$ ). In addition, three signals located at $\delta_{\mathrm{H}} 4.06,4.04$, and $3.99(3 \mathrm{H}, \mathrm{s})$ showed three methoxyl groups.

The ${ }^{13} \mathrm{C}$-NMR spectrum $(150 \mathrm{MHz}$, DMSO- $d 6, \mathrm{ppm}$ ) of compound $\mathbf{2}$ displayed seventeen carbon signals that could be described as follows. The spectrum showed 17 signals, of which 14 signals were assigned to the ellagic acid portion and the rest signals were three methoxyl groups. Two carbon signals located at $\delta_{\mathrm{C}} 158.52$ and 158.32 confirming clearly for two carbonyl groups [C- $\left.7\left(7^{\prime}\right)\right]$ were attributed to ellagic acid lactone carbonyl signals, two carbon signals at $\delta_{C}$ 153.71 and 153.06 confirmed as benzene ring attached by methoxyl and hydroxyl groups [C4(4')], and two carbon signals at $\delta_{\mathrm{C}} 112.49$ and 107.44 indicated benzene ring attached by hydrogen $\left[\mathrm{C}-5\left(5^{\prime}\right)\right]$. Then, two carbon signals located at $\delta_{\mathrm{C}} 141.48$ and 140.28 with high intensity indicated as benzene ring attached by methoxyl groups [C-3(3')]. For a while, two carbon signals on the position of $\delta_{\mathrm{C}} 140.95$ and 140.77 represented benzene ring attached by the respect lactone groups $\left[\mathrm{C}-2\left(2^{\prime}\right)\right]$ and $\delta_{\mathrm{C}}$ 113.44 and 111.84 revealed benzene ring attached by carboxyl groups [C-6(6')]. Finally, two carbon signals located at $\delta_{\mathrm{C}} 111.76$ and 110.89 revealed benzene ring attached by other phenyl group and vice versa $\left[\mathrm{C}-1\left(1^{\prime}\right)\right]$ and assigned as ellagic acid skeleton.

The assignments of all protonated carbons of compound $\mathbf{2}$ were accomplished by interpretation of the HSQC NMR spectrum indicated five connections between: $\delta 7.52(\mathrm{H}$ 5) and 107.44 (C-5), $\delta 7.61(\mathrm{H}-5$ ') and 112.49 $\left(\mathrm{H}-5\right.$ '),$\delta 4.06$ and $60.92\left(3^{\prime}-\mathrm{OCH}_{3}\right), \delta 4.04$ and $61.28\left(3-\mathrm{OCH}_{3}\right)$, and $\delta 3.99$ and 56.70 (4$\mathrm{OCH}_{3}$ ). The comparison of ${ }^{1} \mathrm{H}-$ and ${ }^{13} \mathrm{C}-\mathrm{NMR}$ spectral data of compound $\mathbf{2}$ and that were identical with those reported in literature data (Hiranrat, 2010; Gao, Hu, \& Li, 2012) might be justified that the compound is 3,4,3'-tri- $O$ methylellagic acid.

There are no previous reports regarding the investigation of chemical components of $S$. polycephalum stem bark especially for phenolic compounds. In this study, two phenolic compounds were now successfully isolated from chloroform fraction of the plant that are gallic acid (1) and 3,4,3'-tri- $O$ methylellagic acid (2). Both compounds were found from the plant for the first time.

In chemical, gallic acid (1) is known as 3,4,5-trihydroxybenzoic acid. Gallic acid (1) that is phenolic compound is an important molecule which exists either in free form or as a part of the tannin molecule. Naturally occurring plant tannins are major source of raw material for production of gallic acid (1) (Shubhi, Vandana, Kshipra, \& Paul, 2013). The products of bioconversion of hydrolysable tannins by tannin acyl hydrolase (called tannase) are gallic acid (1) (Shilpa, 2010). It was reported that gallic acid (1) and ellagic acid are main phytoconstituents and active principles of $S$. cumini (Damle \& Dalavi, 
2015). These organic acids had also been found from 14 edible Myrtaceae fruits: Eugenia aggregata, E. brasiliensis, E. luschnathiana, E. reinwardtiana, Myrciaria cauliflora, M. dubia, M. vexator, Syzygium cumini, $S$. curranii, $S$. jambos, $S$. javanicum, $S$. malaccense, $S$. samarangense, and $S$. samarangense var. Taiwan pink (Shubhi, et al., 2013). But, in this study ellagic acid has not been found from the plant.

Meanwhile, 3,4,3'-tri- $O$-methylellagic acid (2) that is also phenolic compound is an ellagic acid derivative. In chemically, the structure of this compound possess ellagic skeleton as shown in Figure 3. Indeed, 3,4,3'tri- $O$-methylellagic acid (2) is ellagic acid with the hydroxyl $(-\mathrm{OH})$ groups at position C-3, C4 and $\mathrm{C}-3$ ' are replaced by methoxyl $\left(-\mathrm{OCH}_{3}\right)$ groups. With methoxylated ellagic acid, this compound becomes more non-polar and insoluble in chloroform. So, 3,4,3'-tri- $O$ methylellagic acid (2) can be formed and derived from the chloroform extract.

The diversity and complexity of ellagic acid derivatives is actually determined on the type and amount of functional groups which can replace the hydroxyl groups either by methoxyl groups and the glycosyl groups mostly at position C-3, C-4, C-3' and C-4'. From here, for instance 3,3'-di- $O$-methylellagic acid (Reynertson, 2007), ellagic acid 4-O- $\alpha$-L-2"acetylrhamnopyranoside, 3-O-methylellagic acid 3'-O- $\alpha$-L-rhamnopyranoside, $\quad 3-O$ methylellagic acid 3'-O- $\beta$-D-glucopyranoside (Simoes-Pires et al., 2009) has been isolated from $S$. cumini, beside ellagic acid its self (Simoes-Pires et al., 2009; De Bona et al., 2016).<smiles></smiles>

Figure 3. Skeletal formula of ellagic acid

The other examples of ellagic acid derivatives are 3-O-ellagic acid-4'-O- $\alpha$ rhamnopyranoside, ellagic acid rhamnopyranoside, 3-O-methylellagic acid4'-O- $\alpha-2$ "- $O$-acetylrhamnopyranoside, and 3-O-methylellagic acid-4' $-O-\alpha-3$ "'-O- acetylrhamnopyranoside obtained from $S$. guineense stem bark (Djoukeng, Mansour, Tapondjou, Lontsi \& Tabacchi, 2007; Khan, Khan, Sahreen, \& Ahmed, 2012). Then, from the methanolic extract of $S$. Jambos leaf had been known containing ellagic acid derivatives: 3,3',4'-tri-O-methylellagic acid-4$O-\beta$-D-glucopyranoside and 3,3',4'-tri- $O$ methylellagic acid (Djipa, Delme'e, \& Leclercq, 2000). Therefore, ellagic acid derivatives are well known in the Syzygium genera (Myrtaceae).

However, phenolic compounds is often found in Myrtaceae plants, especially the genus Syzygium, such as S. zeylanicum (Anoop \& Bindu, 2014), S. cumini (Ruan, Liang, \& Yi, 2008; Pranoti \& Pragya, 2014), S. samarangense (Edema \& Alaga, 2012), S. polyanthum (Har \& Ismail, 2012) and $S$. cordatum (Sidney, Siyabonga, \& Kotze, 2015), etc. But the phenolic compound gallic acid is still very little found in Syzygium plants. Some of Syzygium plants containing the compound are S. cumini (Swami, Thakor, Patil, \& Haldankar, 2012), S. litorale (Tukiran, Mahmudah, Hidayati, \& Shimizu, 2016), and $S$. polyanthum (Nurlaila, 2016). Thus, it is expected that many other phenolic compounds will be found in S. polycephalum, in addition to the two compounds. Therefore, an intensive investigation of the chemical components in the plant is strongly needed to be done.

\section{CONCLUSIONS}

Phytochemical investigations of the chloroform fraction of $S$. polycephalum stem bark led to the isolation of two phenolic compounds: gallic acid (1) and 3,4,3'-tri- $O$ methylellagic acid (2). Structurally, compound $\mathbf{2}$ is a derivative compound of ellagic acid in which the acid itself is formed from two gallic acids. This means it is very reasonable that two compounds are equally found in one plant including the plant.

\section{ACKNOWLEDGEMENTS}

This work was partially supported by the Directorate of Research and Community Service, the Ministry of Research, Technology and High Education, for financial support to our project in the FUNDAMENTAL RESEARCH Schema-2016 (Grant Number: 294/UN38/HK/LT/2016, March 1, 2016). We 
wish to thank also deeply thanks to Hyiya Amen for help us to measure NMR and LCESI-MS.

\section{REFERENCES}

Anoop, M.V. \& Bindu, A.R. (2014). Pharmacognostic and physico-chemical studies on leaves of Syzygium zeylanicum (L.) D.C., International Journal of Pharmacognosy and Phytochemical Research, 6(4), 685-689.

Ariyanti, E.E., Rony, I., Lia, H., \& Deden, M. (2012). Distribution of Syzygium spp. (klampok) in some areas of Bromo Tengger Semeru National Park, East Java. Proceeding of Society Indonesian Biodiversity International Conference, 1,135142 .

Baliga, M.S., Harshith, P.B., Bantwal, R.V.B., Rajesh, W., \& Princy, L.P. (2011). Phytochemistry, traditional uses and pharmacology of Eugenia jambolana Lam. (black plum): a review, Food Research International, xxx: 1-14.doi: 10.1016/j.foodres.2011.02.007.

Barbosa, L.C.A., Cleber, J.S., Róbson, R.T., Renata, M.S.A.M., \& Antônio, L.P. (2013). Chemistry and biological activities of essential oils from Melaleuca L. species, Agriculturae Conspectus Scientificus. 78(1), 11-23.

Damle, M. \& Nilam, D. (2015). Development and validation of stability indicating HPLC method for determination of ellagic and gallic acids in jambul seeds (Syzygium cumini), International Journal of Applied Sciences and Biotechnology, 3(3): 434-438. doi: 10.3126./ijasbt.v3i3.12908.

De Bona, K.S., Bonfanti, G., Bitencourt, P.E., da Silva, T.P., Borges, R.M., Boligon, A., Pigatto, A., Athayde, M.L., \& Moretto, M.B. (2016). Protective effect of gallic acid and Syzygium cumini extract against oxidative stress-induced cellular injury in human lymphocytes, Drug and Chemical Toxicology. 39(3), 256-263.doi:

10.3109/01480545.2015.1084631.

Djipa, C.D., Delmée, M., \& Quetin-Leclercq, J. (2000). Antimicrobial activity of bark extracts of Syzygium jambos (L.) Alston (Myrtaceae). Journal of Ethnopharmacology, 71, 307-313.
Djoukeng, J.D., Eliane, A.-M., Leon, A.T., David, L., \& Raffaele, T. (2007). Identification of ellagic acid derivatives from stem bark of Syzygium guineense (Myrtaceae), Natural Product Communications. 2, 1-6.

Edema, M.O. \& T.O. Alaga. (2012). Comparative evaluation of bioactive compounds in Hibiscus sabdariffa and Syzygium samarangense juice extracts. African Crop Science Journal, 20, 179 187.

Gao, Y., Hu, Q., \& Li, X. (2012). Chemical composition and antioxidant activity of essential oil from Syzygium samarangense (BL.) Merr. et Perry flower-bud. Spatula DD, 2(1), 23-33. doi: $10.5455 /$ spatula.20120126062707.

Har, L.-W., \& Ismail, I.S. (2012). Antioxidant activity, total phenolics and total flavonoid of Syzygium polyanthum (Wight) Walp leaves. International Journal of Medicinal and Aromatic Plants. 2(2), 219-228.

Hiranrat, A. (2010). Chemical constituents from Rhodomyrtus tomentosa (Aiton) Hassk and antibacterial activity, Thesis, Copyright of Prince of Songkla University.

Jemi, R., Wasrin, S., Fauzi, F., \& Muhammad, H. (2010). Sifat anti jamur kayu kupa (Syzygium polycephalum (Miq.)). Jurnal Ilmu dan Teknologi Kayu Tropis, 8, 93110.

Khan, R.A., Khan, M.R., Sahreen, S., \& Ahmed, M. (2012). Evaluation of phenolic contents and antioxidant activity of various solvent extracts of Sonchusasper (L.) Hill. Chemistry Central Journal, 6(12), 1-7.doi: 10.1186/1752-153X-6-12.

Mohanan, N., Vrinda, K.B., Padmesh, P., Suresh, P.K.K., Mathew, D., Sreekumar, S., Biju, S.R.S., Rasiya, S.B., Kumar, S.K.P.P., \& Anil J. (2015). Jawaharlal Nehru Tropical Botanic Garden and Research Institute (JNTBGRI) Annual Report 2012-13 \& 2014-15, 15-17.

Nurlaila, E. (2016). Identifikasi senyawa antioksidan hasil isolasi dari ekstrak kloroform kulit batang tumbuhan salam (Syzygium polyanthum), A Theses, Submitted to the Faculty of Mathematics and Natural Sciences (in partial fulfillment of the requirements for the 
Science Undergraduate Degree), Universitas Negeri Surabaya, Indonesia, 71-76.

Palanisamy, U.D., Ling, L.T., Manaharan, T., Sivapalan, V., Subramaniam, T., Helme, M.H., \& Masilamani, T. (2011). Standardized extract of Syzygium aqueum: a safe cosmetic ingredient. International Journal of Cosmetic Science, 33(3), 269-275. doi: 10.1111/j.1468-2494.2010.00637.x.

Pranoti B. \& Pragya G. (2014). In vitro evaluation of phytochemical and antioxidant properties of Syzygium cumini leaves and their synergistic effect on its antimicrobial property. International Journal of Research in Pharmaceutical Sciences. 5, 254-258.

Preddy, V. (2014). Cancer: oxidative Stress and dietary antioxidants. Chapter 10: The Indian blackberry (Jamun), antioxidant capacity, and cancer protection (authorized by Farrukh Aqil, Radha Munagala, Jeyaprakash Jeyabalan, Thwisha Joshi, Ramesh C. Gupta), 101.

Ragasa, C.Y., Torres, O.B., Shen, C.-C., Lachica, M.K.E.G., Sulit, A.B., Chua, D.B.D.L., Ancheta, A.D.M., Ismail, C.J.B., Bernaldez, F.T.E., \& Raga, D.D. (2014). Triterpenes from the leaves of Syzygium polycephalum, S. cumini, and S. samarangense, Chemistry of Natural Compounds, 50(5), 942-944.

Reynertson, K.A. (2007). Phytochemical analysis of bioactive constituents from edible Myrtaceae fruits. A Dissertation Submitted to the Graduate Faculty in Biology in partial fulfillment of the requirements for the Degree of Doctor of Philosophy, The City University of New York.

Ruan, Z.P., Liang, L.Z., \& Yi, M.L. (2008). Evaluation of the antioxidant activity of
Syzygium cumini leaves. Molecules, 13, 2545-2556. doi: 10.3390/ molecules 13102545 .

Shilpa, A.W. (2010). Bioconversion of tannic acid to gallic acid by using fungal tannase, A Theses Submitted to the Division of Biochemical Sciences, National Chemical Laboratory, Pune 411008 (India), 7-10.

Shubhi, M., Kirar, V., Misra, K., \& Nandi, S.P. (2013). Quantitative estimation of gallic acid in Rosa sinensis, Emblica officinalis, and Syzygium aromatocium by HPTLC. International Research Journal of Pharmacy, 4(7): 87-89. Doi: 10.7897/2230-8407.04719.

Sidney, M.T., Shandu, J.S., \& Basson, A.K. (2015). The antibacterial and antidiarreal activities of the crude methanolic Syzygium cordatum [S.Ncik, 48 (UZ)] fruit pulp and seed extracts. Journal of Medicinal Plants Research, 9(33), 884891. doi: 10.5897/JMPR2015.5789.

Simões-Pires, C.A., Vargas, S., Marston, A,. Ioset, J.R., Paulo, M,Q, Matheeussen, A., \& Maes, L. (2009). Ellagic acid derivatives from Syzygium cumini stem bark: investigation of their antiplasmodial activity. Natural Product Communications, 4(10), 1371- 1376.

Swami, S.B., Nayan, S.J.T., Meghatai, M.P., \& Parag, M.H. (2012). Jamun (Syzygium cumini (L.)): a review of its food and medicinal uses. Food and Nutrition Sciences, 3, 1100-1117. doi.org: 10.4236/fns.2012.38146.

Tukiran, Fitriyatul, M., Nurul, H., \& Kuniyoshi, S. (2016). A phenolic acid and its antioxidant activity from stem bark of chloroform fraction of Syzygium litorale (Blume) Amshoff (Myrtaceae). Molekul, 11(2), 180-189. doi: 10.20884/1.jm.2016.11.2.215. 